\title{
РАЗДЕЛ ХІ. ЮРИСПРУ ДЕНЦИЯ
}

\author{
Марченко А.В., Марченко В.В. \\ К вопросу нормативного обеспечения отказа в выдачи (экстрадиции) в \\ Российском законодательстве
}

Санкт-Петербургский государственный морской технический университет (СПбГМТУ)

(Россия, Санкт-Петербург)

doi: $10.18411 /$ scienceconf-05-2020-25

idsp: scienceconf-05-2020-25

\section{Аннотация}

Рассматривается проблема соблюдения прав человека и гражданина при осуществлении экстрадиции (выдачи) лиц, совершивших преступления. Исследуются правовые основания отказа в выдаче преступников на основе действующего уголовнопроцессуального закона и договоров Российской Федерации. Приводятся взгляды различных авторов на исследуемую проблему. Отмечается необходимость совершенствования и унификации института отказа в выдаче в соответствии с потребностями практики оказание правовой помощи в уголовной сфере.

Ключевые слова: экстрадиция (выдача), соблюдение прав и свобод человека, отказ в выдаче преступников, основания отказа в выдаче преступников, оказание правовой помощи в уголовной сфере.

\section{Abstract}

The problem of respect for human and civil rights in the extradition (extradition) of persons who have committed crimes is considered. The article examines the legal grounds for refusing to extradite criminals on the basis of the current criminal procedure law and agreements of the Russian Federation. The views of various authors on the problem under study are given. There is a need to improve and unify the institution of refusal of extradition in accordance with the needs of the practice of providing legal assistance in the criminal sphere.

Key words: extradition, protection of human rights and freedoms, refusal to extradite criminals, grounds for refusing to extradite criminals, provide legal assistance in criminal law.

Применительно к экстрадиции (выдаче) лица для уголовного преследования или исполнения приговора необходимо подчеркнуть, что это один из самых сложных и в то же время эффективных видов международного сотрудничества. Помимо соблюдения обязательных правил (двойная криминальность, определенный срок наказания), существуют общепризнанные исключения из сотрудничества по вопросам выдачи, называемые перечнем оснований для отказа в ней. Исходя из правовой природы и назначения правового института отказа в выдаче, он носит ярко выраженный правозащитный характер. Отметим, что на протяжении длительного времени своего существования в России он развивался и совершенствовался в русле общемировых тенденций и отличался своей основательностью и достаточной разработанностью.

Не ставя перед собой цели тщательного анализа перечня оснований отказа в выдаче для уголовного преследования или исполнения приговора как на международном, так и на национальном уровне, скажем лишь, что «есть общепризнанные, обязательные и факультативные основания, их количество не везде одинаково, а их перечень может носить как открытый, так и закрытый характер» $[14, \mathrm{c}$. 23-26]. 
Включение некоторых из них в Конституцию Российской Федерации [7] в первую очередь свидетельствует об их значимости и, соответственно, распространенности применения.

Речь идет о ст.ст. 61 и 63 Конституции РФ.

Статья 61 провозглашает: «Гражданин Российской Федерации не может быть выслан за пределы Российской Федерации или выдан другому государству».

В статье 63 говорится:

1. «Российская Федерация предоставляет политическое убежище иностранным гражданам и лицам без гражданства в соответствии с общепринятыми нормами международного права.

2. В Российской Федерации не допускается выдача другим государствам лиц, преследуемых за политические убеждения, а также за действия (или бездействие), не признаваемые в Российской Федерации преступными...».

В последнем случае соединяются два основания для отказа: в случае преследования за политические убеждения и несоблюдение правила двойной криминальности.

Таким образом, в Конституции РФ закреплено три основания для отказа в выдаче лица для уголовного преследования или исполнения приговора.

Не случайно вышеуказанные основания отказа в выдаче закреплены в Конституции РФ как основополагающие, т.к. в информационно-аналитических сведениях Главного управления международно-правового сотрудничества Генеральной прокуратуры Российской Федерации, в состав которого вошли управление экстрадиции, управление правовой помощи и управление международного права [16], первое место по числу отказов занимает именно наличие у запрошенного лица российского гражданства.

Примечательно, что «подавляющее большинство государств отказывают в экстрадиции собственных граждан и в соответствии с внутренним законодательством могут привлечь виновного к уголовной ответственности либо вообще не осуществлять уголовного преследования (в частности, это относится к совершению деяния, не рассматриваемого по законодательству страны гражданства индивида в качестве преступления)» [18, с. 227].

Особая важность гражданства заключается в его непрерывности и длительности, именно эти обстоятельства существенно отличают его от временного пребывания иностранцев на территории того или иного государства. Наличие определенного гражданско-правового статуса лица обусловливает решение вопросов привлечения к уголовной ответственности.

Несмотря на конституционность данных положений, рассматриваемый вопрос не так однозначен, и было бы неправильным не остановиться на ином подходе.

Это объясняется распространенностью ситуаций, когда лица, совершившие преступления, посягающие на интересы других государств или их граждан (подданных), затем скрываются на территории своего гражданства именно с целью укрыться от уголовного преследования. И здесь возникает определенное противоречие между проведением эффективного расследования по месту совершения преступления и ограничением суверенитета соответствующего государства.

Как уже отмечалось, помимо этого ситуация может осложниться тем, что в запросе о выдаче [21, с. 129] указывается деяние, которое в запрашиваемом государстве не является преступлением. Таким образом, речь идет сразу о двух основаниях для отказа в выдаче для уголовного преследования или исполнения приговора.

Можно предположить, что в силу этих обстоятельств данные основания отказа в выдаче закреплены в Конституции РФ, т.е. на самом высоком нормативно-правовом уровне. 
Отсюда можно констатировать, что в Конституции четко обозначено процессуальное положение выдаваемых лиц - обвиняемые и осужденные, и назван уровень регламентирующих выдачу нормативных правовых актов - федеральный закон и международный договор Российской Федерации. Из этого положения вытекает запрет на выдачу при отсутствии международного договора Российской Федерации и следует исключение применения иных нормативных актов, к коим относятся и нератифицированные международные договоры [13, с. 147].

Как известно, правовые системы, в которые входят страны, оказывают существенное влияние на развитие тех или иных правовых институтов, и применительно к рассматриваемой проблеме принцип невыдачи собственных граждан вообще и закрепление его на конституционном уровне в частности присущ в большей степени странам континентальной (смешанной) правовой системы.

Характерно, что даже тенденции последнего времени к взаимопроникновению отдельных элементов одной правовой системы в другую не смогли повлиять на сложившиеся традиции в данной сфере. Есть, правда, некоторые отступления, применяемые в рамках Европейского союза, допускающие выдачу собственных граждан в определенных случаях в страны Европейского союза соответственно.

Обычно подобная практика отклонения от принципа невыдачи собственных граждан закрепляется, как правило, на основе специальных международных соглашений.

В любом случае немаловажную роль играет установление гражданства лица, запрошенного к выдаче. Не останавливаясь подробно на наличии множественного (двойного и т.д.) гражданства, отметим лишь, что каждое государство, выступающее в роли запрашиваемого, рассматривает наличие своего в качестве приоритетного.

Возвращаясь к Конституции РФ, следует обратить внимание на то, что в ст. 62 закреплено как право на получение двойного гражданства, так и приоритетность российского гражданства применительно к правам, свободам и обязанностям, вытекающим из него.

Говоря о тесной связи гражданства с правовым институтом отказа в экстрадиции, обратим внимание на существующий в практике международного сотрудничества подход, связанный с наличием двойного гражданства и приоритетом преимущественного проживания на территории одного из государств. «Особенно это важно в ситуации, когда лицо, совершившее преступление, имеет двойное гражданство, но находится на территории третьего государства, которое и должно принимать решение о выдаче или отказе в ней» [14, с. 23-26].

В Российской Федерации, как и во многих других странах, Конституция РФ регламентирует право приобретения двойного гражданства в соответствии с федеральным законом или международным договором.

Еще одним сложным в практическом разрешении вопросом является момент получения гражданства: получено оно до или после совершения преступления. К сожалению, нередки случаи, когда целью приобретения гражданства является именно уход от уголовной ответственности.

В правовой доктрине устоялось мнение, разделяемое большинством государств, о невыдаче собственных граждан вне зависимости от цели и времени получения гражданства, главное - его наличие на момент получения запроса о выдаче данного лица. Однако в юридической литературе неоднократно высказывалось мнение о том, что факт получения гражданства уже после совершения преступления, за которое запрашивается выдача, не должен служить основанием для отказа в ней. Таким образом, действующая Конституция РФ стоит на страже прав и свобод не только российских, но и иностранных граждан и лиц без гражданства.

Рассматривая вопросы правового регулирования отказа в выдаче, также следует обратиться к действующему уголовно-процессуальному законодательству Российской 
Федерации. Отказ в выдаче лица должен быть обусловлен одним или несколькими законодательными ограничениями, оговоренными в ст. 464 Уголовно-процессуального кодекса РФ [9].

Как правило, любые реформы направлены на упрощение нормы и повышение ее эффективности в правоприменении. Именно с этой точки зрения следует рассмотреть изменения, внесенные в ст. 464 УПК РФ [11].

На протяжении длительного периода Россия в своей внешней политике придерживается позиции укрепления международной законности как главного направления своей деятельности на международной арене.

«Применительно к проблемам отказа в выдаче (экстрадиции) помимо договоров основополагающее значение имеют международно-правовые обычаи, базирующиеся на принципах суверенитета и равенства - обязательных для всех» [14, с. 27]. Международная практика, несмотря на то, что не отражена в международных документах, также признается в качестве международного обычая.

Общепризнано, что в вопросах международного сотрудничества в сфере уголовного производства очень важно соблюдать баланс между осуществлением борьбы с транснациональной преступностью и обеспечением прав и свобод человека и гражданина. Применительно к выдаче лица для уголовного преследования или исполнения приговора это обеспечение неотвратимости наказания за содеянное и защита прав и свобод запрошенного к выдаче лица.

В нашем случае институт отказа в выдаче лица по определению носит правозащитный характер.

Обращаясь к истории становления и развития самого института отказа в выдаче, можем констатировать, что оно проходило в русле общемировых тенденций и международной практики и отличалось надлежащей проработанностью (например, закон Российской империи о выдаче 1911 года[17]).

Несмотря на прошлую некоторую закрытость (изолированность) СССР, наша страна имеет обширный опыт взаимоотношений в вопросах международного сотрудничества в сфере уголовного судопроизводства и зарекомендовала себя в качестве надежного партнера, исполняющего свои обязательства, в том числе и применительно к отказу в выдаче.

Отказ сам по себе означает отрицательный ответ на просьбу, требование или какое-либо предложение. В данном случае отказ в выдаче - это неотъемлемое право запрашиваемого государства, как на международном уровне, так и национальном.

«Отказывая в выдаче, государство в лице своих компетентных органов (в России это Генеральный прокурор Российской Федерации или его заместитель) ссылается на соответствующие нормы, тем самым обосновывая свое решение» [15, с. 27].

Правовая база отказа в выдаче достаточно велика: все основополагающие конвенции и двусторонние договоры, регламентирующие выдачу (экстрадицию), соответственно предусматривают и перечень оснований для отказа в ней. Примерно он везде одинаков как по содержанию, так и по объему. Интересна эта норма и по своему построению: как правило, она состоит из двух частей - основания, носящие обязательный характер, и факультативные. Третья часть предписывает обязательное уведомление запрашивающего государства. Российский законодатель в свое время пошел по традиционному пути.

Действующая ныне ст. 446 УПК РФ «Отказ в выдаче лица» один раз подверглась совершенно обоснованному изменению. Так, в 2009 г. из разряда факультативных в обязательные было перенесено основание для отказа в выдаче лица «деяние, послужившее основанием для запроса о выдаче, не является по уголовному закону преступлением». То есть лицо не выдается в том случае, если в запросе указано деяние, которое по уголовному закону запрашиваемого государства не является преступлением. Такой подход основан на общепризнанных принципах, которыми руководствуются государства при заключении многосторонних конвенций и 
двусторонних договоров по вопросам выдачи. При всех различиях стран континентальной и общей правовых систем в подходах к вопросам выдачи они твердо придерживаются трех базовых принципов: преступление должно быть экстрадиционным, за совершение которого предусмотрена выдача (наказание свыше одного года и более тяжкое); наличие двойной преступности, или двойной криминальности, т.е. оно должно быть преступлением по законодательству обоих договаривающихся государств; и ограничение в преследовании выданного лица или правило конкретности, в соответствии с которым лицо преследуется только за преступление, указанное в запросе.

Таким образом, сейчас ст. 446 УПК РФ содержит, следующие шесть обязательных оснований отказа в выдаче:

- лицо, в отношении которого поступил запрос иностранного государства о выдаче, является гражданином Российской Федерации;

- лицу, в отношении которого поступил запрос иностранного государства о выдаче, предоставлено убежище в Российской Федерации в связи с возможностью преследований в данном государстве по признаку расы, вероисповедания, гражданства, национальности, принадлежности к определенной социальной группе или по политическим убеждениям;

- в отношении указанного в запросе лица на территории Российской Федерации за то же самое деяние вынесен вступивший в законную силу приговор или прекращено производство по уголовному делу;

- в соответствии с законодательством Российской Федерации уголовное дело не может быть возбуждено или приговор не может быть приведен в исполнение вследствие истечения сроков давности или по иному законному основанию;

— имеется вступившее в законную силу решение суда Российской Федерации о наличии препятствий для выдачи данного лица в соответствии с законодательством и международными договорами Российской Федерации;

- деяние, послужившее основанием для запроса иностранного государства о выдаче, в соответствии с уголовным законодательством Российской Федерации не является преступлением [8].

Три факультативных основания для отказа в выдаче:

- деяние, в связи с которым направлен запрос о выдаче, совершено на территории Российской Федерации или против интересов Российской Федерации за пределами ее территории;

- за то же самое деяние в Российской Федерации осуществляется уголовное преследование лица, в отношении которого направлен запрос о выдаче;

— уголовное преследование лица, в отношении которого направлен запрос о выдаче, возбуждается в порядке частного обвинения.

В тоже время, Пленум Верховного Суда РФ от 14 июня 2012 г. № 11 обращает внимание судов на то, что условия и основания отказа в выдаче предусматриваются не только в УПК РФ, иных законах, но и в международных договорах Российской Федерации [12].

Например, как следует из п. 1 ст. 10 и п. 4 ст. 12 Федерального закона «О беженцах» [10], статей 32 и 33 Конвенции о статусе беженцев от 28 июля 1951 года, лицо, признанное беженцем или получившее временное убежище, в отношении которого Российской Федерацией получен запрос о выдаче, не может быть выдано запрашивающему государству, которое является государством гражданской принадлежности, обычного местожительства такого лица или любым иным государством, на территории которого имели место обстоятельства, послужившие основанием для предоставления лицу временного убежища или статуса беженца. 
В постановлении Конституционного Суда РФ от 31.07.1995 г., отмечено, что «международные договоры являются согласно статье 15 (часть 4) Конституции Российской Федерации составной частью её правовой системы и должны добросовестно соблюдаться, в том числе путём их учёта внутренним законодательством» [20]. Следует отметить, что Российская Федерация с 1992 г. осуществляет выдачу на основе двусторонних Договоров о правовой помощи с суверенными государствами: Литвой, Азербайджаном, Киргизией. В 1993 г. заключены аналогичные договоры с Латвией, Эстонией и Молдовой [19]. Но главным является международный акт, заключенный Российской Федерацией 22 января 1993 г. в Минске [5].

Процедура выдачи по Минской конвенции не имеет существенных различий с правилами других международных договоров России со странами, бывшими союзными республиками СССР. Регулируя право невыдачи - участники Конвенции договорились о том, что они в праве отказать в выдаче требуемого лица, если: лицо, выдача которого требуется, является гражданином запрашиваемой Договаривающейся Стороны Россия не выдаёт своих граждан, совершивших преступление на территории других государств. Согласно ст. 62 Договора между РФ и Азербайджанской Республикой 1992 г., ст. 62 Договора между РФ и Республикой Кыргызстан 1992 г., ст. 57 Конвенции СНГ 1993 г., выдача не имеет места, если преступление в соответствии с законодательством запрашивающей или запрашиваемой сторон преследуется в порядке частного обвинения.

Иногда в договорах зафиксирован более широкий перечень относительных оснований. Так, по Договору между РФ и КНР о выдаче 1995 г. (ст. 4) запрашиваемая сторона может отказать в выдаче в любом из следующих случаев [6]:

1) в соответствии с законодательством запрашиваемой стороны она обладает юрисдикцией в отношении лица, выдача которого запрошена, или преступления, в связи с которым направлена просьба о выдаче. В таком случае запрашиваемая сторона должна по просьбе запрашивающей стороны возбудить уголовное преследование в отношении этого лица;

2) если запрашиваемая сторона, принимая во внимание характер преступления и интересы запрашивающей стороны, сочтёт, что, исходя из обстоятельств уголовного дела, выдача данного лица не отвечает принципу гуманности ввиду возраста, состояния здоровья или других личностных обстоятельств этого лица;

3) запрашиваемая сторона осуществляет уголовное преследование за то же преступление в отношении лица, чья выдача требуется». Как видим, пункты 1 и 3 закрепляют юридические основания отказа в выдаче, п. 2 отражает общую тенденцию гуманизации сотрудничества в сфере уголовного процесса.

По Европейской конвенции о выдаче 1957 г. выдача также может не осуществляться за фискальные преступления (ст. 5) [4].

Согласно ст. 2 Конвенции о защите прав человека и основных свобод [1], в толковании Европейского Суда по правам человека, ст. 11 Европейской конвенции о выдаче лицо не подлежит выдаче в случае, если преступление, в связи с которым запрашивается выдача, наказуемо смертной казнью в соответствии с законом запрашивающего государства и такое государство не предоставит гарантий, которые Российская Федерация сочтет достаточными, что наказание в виде смертной казни не будет приведено в исполнение. Указанными гарантиями могут являться положения законодательства, запрещающие применять смертную казнь в запрашивающем государстве, заверения со стороны правоохранительных либо иных компетентных органов указанного государства, что в случае назначения лицу наказания в виде смертной казни оно не будет приведено в исполнение.

Судам необходимо иметь в виду, что в соответствии со ст. 7 Международного пакта о гражданских и политических правах [2], в толковании Комитета ООН по 
правам человека, ст. 3 Конвенции против пыток и других жестоких, бесчеловечных или унижающих достоинство видов обращения и наказания от 10 декабря 1984 года [3] лицо также не подлежит выдаче в случае, если имеются серьезные основания полагать, что в запрашивающем государстве оно может быть подвергнуто не только пыткам, но и бесчеловечному либо унижающему человеческое достоинство обращению или наказанию.

Также следует учитывать, что в п. 9 Пленума Верховного Суда РФ от 14 июня 2012 г. № 11 отмечено, что принятие в Российской Федерации либо в запрашивающем или ином государстве акта об амнистии, распространяющегося на преступление, в связи с совершением которого поступил запрос о выдаче, является основанием к отказу в выдаче в том случае, если это предусматривается международным договором Российской Федерации. Например, в соответствии со ст. 2 Дополнительного протокола к Европейской конвенции о выдаче от 15 октября 1975 года лицо не подлежит выдаче запрашивающему государству - участнику данного Протокола, если в третьем государстве, участвующем в Европейской конвенции о выдаче, по делу данного лица было вынесено окончательное судебное решение и применен акт об амнистии, освобождающий его от наказания в виде лишения свободы. Согласно ст. 4 Второго дополнительного протокола к Европейской конвенции о выдаче от 17 марта 1978 года выдача в государство, являющееся участником указанного Протокола, не допускается, если в Российской Федерации в отношении преступления, в связи с совершением которого был направлен запрос о выдаче, был принят акт об амнистии и Российская Федерация обладала компетенцией возбуждать уголовное преследование согласно статьям 11, 12 УК РФ.

Данный широкий круг оснований для отказа в выдаче порождает дискуссии среди ученых, и естественно вырабатываются предложения по поправкам в УПК РФ, что позволит увеличивать данные основания до бесконечности [15, с. 26-29].

Сравнение статьи 446 УПК РФ, договоров и иных нормативных актов позволяет сделать определенные выводы, что перечень оснований для отказа в выдаче носит открытый характер, и все новые основания вполне охватываются положением «и иному законному основанию».

Таким образом, условия и основания отказа в выдаче предусмотрены не только в УПК РФ, иных законах, но и в международных договорах Российской Федерации. Вместе с тем, если выдача лица не производится, независимо от вида нормативного правового акта, в которых они содержатся, Генеральная прокуратура РФ обязана уведомить об этом компетентные органы соответствующего иностранного государства с указанием конкретных оснований отказа.

В правовой доктрине основополагающей тенденцией развития института отказа в выдаче является упрощение процедуры, и здесь, на наш взгляд, основной задачей как раз и станет сокращение перечня оснований и его закрытый характер, а не, наоборот, установление конкретного срока для принятия решения, незамедлительное уведомление запрашивающей стороны и др.

Второй тенденцией является расширение круга лиц, которые могут быть выданы, и перечня преступлений, предполагающих выдачу (экстрадицию).

В связи с этим перечень оснований для отказа в выдаче в соответствии с потребностями практики должен быть сокращен, носить закрытый характер, не содержать нечетких формулировок и, самое главное, необходимо установить конкретный срок для принятия решения, а ст. 464 УПК РФ «Отказ в выдаче лица» нуждается в дальнейшей доработке.

$$
* * *
$$

1. Конвенция о защите прав человека и основных свобод ETS N 005 (Рим, 4 ноября 1950 г.). Вступила в силу 3 сентября 1953 г., для РФ 5 мая 1998 г. Ратифицирована РФ ФЗ от 30 марта 1998 г. № 54-Ф3 // Собрание законодательства Российской Федерации. - 2001. - № 2. - Ст. 163. 
2. Международный пакт о гражданских и политических правах (Нью-Йорк, 16 декабря 1966 г.). Вступил в силу 23 марта 1976 г., для СССР 23 марта 1976 г. Ратифицирован Указом Президиума ВС СССР от 18 сентября 1973 г. № 4812-VIII // Ведомости Верховного Совета СССР. - 1976. - № 17. - Ст. 291.

3. Конвенция ООН против пыток и других жестоких, бесчеловечных или унижающих достоинство видов обращения и наказания (Нью-Йорк, 10 декабря 1984 г.). Вступила в силу, в том числе для СССР, 26 июня 1987 г. Ратифицирована Указом Президиума ВС СССР от 21 января 1987 г. № 6416ХІ // Ведомости Верховного Совета СССР. - 1987. - № 45. Ст. 747.

4. Европейская конвенция о выдаче ETS N 024 (заключена в г. Париже 13 декабря 1957 г.). Вступила в силу с 18 апреля 1960 года, для Российской Федерации с 5 июня 2000 г. Ратифицирована Федеральным законом от 26 октября 1999 г. № 190-ФЗ с оговорками и заявлениями. // Собрание законодательства Российской Федерации. - 2000. - № 23. - Ст. 2348.

5. Конвенция о правовой помощи и правовых отношениях по гражданским, семейным и уголовным делам (Заключена в г. Минске 22 января 1993 г.). Вступила в силу 19 мая 1994 г., для Российской Федерации 10 декабря 1994 г. // Собрание законодательства Российской Федерации. - 1995. - № 17. Ст. 1472.

6. Договор между Российской Федерацией и Китайской Народной Республикой о выдаче (подписан в г. Москве 26 июня 1995 г.). Ратифицирован 13 июня 1996 г. // Бюллетень международных договоров. 1996. - № 9.

7. Конституция Российской Федерации от 12 декабря 1993 г. (с учетом поправок от 21 июля 2014 г. № 11-ФКЗ) // Российская газета. - 1993. - 25 декаб. Далее по тексту - Конституция РФ.

8. Уголовный кодекс Российской Федерации от 13 июня 1996 г. № 63-ФЗ (ред. 7 апреля 2020 г. № $195-$ Ф3) // Собрание законодательства Российской Федерации. - 1996. - № 25. - Ст. 2954. Далее по тексту - УК РФ.

9. Уголовно-процессуальный кодекс РФ от 18 декабря 2001 г. № 174-ФЗ (ред. от 24 апреля 2020 г. № 198-Ф3) // Собрание законодательства Российской Федерации. - 2001. - № 52. - Ст. 4921. Далее по тексту - УПК РФ.

10. Федеральный закон от 19 февраля 1993 г. № 4528-І (ред. от 26 июля 2019 г. № 232-Ф3) «О беженцах» // Ведомости Съезда народных депутатов Российской Федерации и Верховного Совета Российской Федерации. - 1993. - № 12. - Ст. 425.

11. Федеральный закон от 4 июля 2003 г. № 92-Ф3 (ред. от 29 декабря 2010 г. № 433-Ф3) «О внесении изменений и дополнений в Уголовно-процессуальный кодекс Российской Федерации» // Собрание законодательства РФ. - 2003. - № 27 (ч. 1). - Ст. 2706; Федеральный закон от 17 декабря 2009 г. № 324-Ф3 «О внесении изменений в статью 59 Уголовного кодекса Российской Федерации и Уголовнопроцессуальный кодекс Российской Федерации» // Собрание законодательства РФ. - 2009. - № 51. Ст. 6161.

12. Постановление Пленума Верховного Суда РФ от 14 июня 2012 г. № 11 (ред. от 3 марта 2015 г. № 9) «О практике рассмотрения судами вопросов, связанных с выдачей лиц для уголовного преследования или исполнения приговора, а также передачей лиц для отбывания наказания» // Бюллетень Верховного Суда Российской Федерации. - 2012. - № 8 .

13. Волженкина В.М. Выдача в российском уголовном процессе. - М.: ООО Изд-во «Юрлитинформ», 2002. - $336 \mathrm{c}$.

14. Выскуб В.С. Конституция Российской Федерации в свете проблем экстрадиции. [Текст] / В.С. Выскуб. // Конституционное и муниципальное право. - 2014. - № 8. - С. 23-26.

15. Выскуб В.С. Проблемные вопросы отказа в выдаче лица для уголовного преследования или исполнения приговора [Текст] / В.С. Выскуб. // Международное уголовное право и международная юстиция. - 2016. - № 3. - С. 27.

16. Официальный сайт Генеральной прокуратуры Российской Федерации [Электронный ресурс]. URL: https:/genproc.gov.ru/ms/ (дата обращения: 12.05.2020).

17. Положения Закона о выдаче 1911 г. по тщательности юридической проработанности не уступает нормам законов и договоров, образующих сегодня правовую базу России по вопросам выдачи (см.: Родионов К.С. Закон Российской Империи 1911 г. об экстрадиции / К.С. Родионов. // Государство и право. - 2003. - № 7. - С. 80-91.).

18. Сафаров Н.А. Экстрадиция в международном уголовном праве: проблемы теории и практики. - М., 2005. $-416 \mathrm{c}$.

19. Сборник международных договоров Российской Федерации по оказанию правовой помощи / Сост.: Крашенинников П.В., Кружков В.П. - М.: Спарк, 1996. - 616 с.

20. Собрание законодательства Российской Федерации. - 1995. - № 33. - Ст. 3424.

21. Шаталов А.С. Правовой механизм сотрудничества в сфере уголовного судопроизводства. [Текст] / А.С. Шаталов. // Право. Журнал Высшей школы экономики. - 2015. - № 1. - С. 129. 